\title{
Low-dose fentanyl-midazolam combination improves sevoflurane induction in adults
}

\section{La combinaison de fentanyl et midazolam à faible dose améliore l'induction au sévoflurane chez l'adulte}

\author{
Sandra Lesage, MD · Pierre Drolet, MD · François Donati, MD, PhD • \\ Sébastien Racine, MSc · Louis-Philippe Fortier, MD · Daniel Audy, MD
}

Received: 27 March 2009/Accepted: 9 July 2009/Published online: 30 July 2009

(C) Canadian Anesthesiologists' Society 2009

\begin{abstract}
Purpose We investigated the effects of a combination of low-dose fentanyl-midazolam premedication on the speed of inhaled induction with sevoflurane and ProSeal ${ }^{T M}$ laryngeal mask airway (PLMA) insertion conditions.

Methods Eighty adult patients undergoing elective surgery were randomized in a double-blind fashion to receive either a normal saline placebo (Group PLAC) or a fentanyl $0.6 \mu \mathrm{g} \cdot \mathrm{kg}^{-1}$ and midazolam $9 \mu \mathrm{g} \cdot \mathrm{kg}^{-1}$ premedication (Group FM) 5 min before tidal volume sevoflurane $8 \% / \mathrm{O}_{2}$ induction. Anxiety levels, times to loss of eyelash reflex (LER) and PLMA insertion, and cardiorespiratory data were recorded.

Results Times to LER (Group PLAC: $66 \pm 34 \mathrm{sec}$ vs Group FM: $47 \pm 18 \mathrm{sec}, P=0.0027$, difference $=19 \mathrm{sec}:$ 95\% confidence interval [CI] 7-31 sec) and to PLMA insertion (Group PLAC: $186 \pm 80 \mathrm{sec}$ vs Group FM: $119 \pm 44$ sec, $P<0.0001$, difference $=68$ sec: $95 \% C I$ 39-97 sec) were shorter following FM. After PLMA insertion, end-tidal sevoflurane concentration (EtSevo) was lower and end-tidal $\mathrm{CO}_{2}\left(\mathrm{EtCO}_{2}\right)$ was higher following FM. Respiratory rate $(R R)$ was lower with $F M$, but there was no difference regarding tidal volume. Adverse events, such as movements and apnea, occurred more often in Group PLAC. Systolic blood pressure (SBP) and heart rate (HR) during induction were both lower with FM. Anxiety level after
\end{abstract}

S. Lesage, MD $(\varangle) \cdot$ P. Drolet, MD · F. Donati, MD, PhD .

S. Racine, MSc · L.-P. Fortier, MD - D. Audy, MD

Department of Anesthesiology, Maisonneuve-Rosemont

Hospital, Université de Montréal, 5415 boulevard de

l'Assomption, Montreal, QC H1T 2M4, Canada

e-mail: sandra.lesage@umontreal.ca premedication was lower following FM administration. All participants remembered the face mask being applied in Group PLAC vs 69\% in Group FM, P $<0.0001$.

Conclusion Administration of a low-dose fentanylmidazolam combination prior to sevoflurane induction decreases time to LER and allows for more rapid and less eventful PLMA insertion. Both SBP and HR were lower when premedication was administered. Patients receiving premedication were less anxious and less likely to remember the face mask. However, premedication was associated with a lower $\mathrm{RR}$ and increased $\mathrm{EtCO}_{2}$ values following PLMA insertion, in spite of lower EtSevo concentrations. (ClinicalTrials.gov ID NCT00723164).

\section{Résumé}

Objectif Nous avons examiné les effets d'une combinaison de fentanyl - midazolam à faible dose en prémédication sur la vitesse d'une induction par inhalation de sévoflurane et sur les conditions d'insertion du masque laryngé Pro$\mathrm{Seal}^{T M}$ (PLMA).

Méthode Quatre-vingts patients adultes subissant une chirurgie non urgente ont été randomisés en double aveugle à recevoir soit un placebo de solution salée (groupe PLAC) ou une prémédication composée de fentanyl 0,6 $\mu \mathrm{g} \cdot \mathrm{kg}^{-1}$ et midazolam $9 \mu \mathrm{g} \cdot \mathrm{kg}^{-1}$ (groupe FM) cinq minutes avant l'induction avec du sévoflurane $8 \% / \mathrm{O}_{2}$ à volume courant. Les niveaux d'anxiété, le temps jusqu'à la perte du réflexe ciliaire (PRC) et l'insertion du PLMA ainsi que les données cardiorespiratoires ont été enregistrées.

Résultats Les temps jusqu'à PRC (groupe PLAC: $66 \pm 34$ secondes vs groupe $F M: 47 \pm 18$ secondes, $P=$ 0,0027 , différence $=19$ secondes $:$ intervalle de confiance [IC] 95 \% 7-31 secondes) et jusqu'à insertion du PLMA (groupe PLAC : $186 \pm 80$ secondes vs groupe FM : $119 \pm$ 44 secondes, $P<0,0001$, différence $=68$ secondes $:$ IC $95 \%$ 
39-97 secondes) étaient plus courts après l'administration de FM. Après l'insertion du PLMA, la concentration télé-expiratoire de sévoflurane (EtSevo) était plus basse et le $\mathrm{CO}_{2}$ télé-expiratoire $(\mathrm{EtCO})$ plus élevé suite à l'administration de FM. La fréquence respiratoire (FR) était plus basse avec FM, mais aucune différence n'a été observée dans le volume courant. Les effets secondaires, tels que les mouvements et l'apnée, sont survenus plus souvent dans le groupe PLAC. La tension systolique (TS) et la fréquence cardiaque (FC) pendant l'induction étaient toutes deux plus basses lors de l'administration de FM. Le niveau d'anxiété après la prémédication était plus faible suite à l'administration de FM. Tous les participants se sont souvenus de l'application du masque facial dans le groupe PLAC vs $69 \%$ dans le groupe $F M, P<0,0001$.

Conclusion L'administration d'une combinaison de fentanyl - midazolam à faible dose avant l'induction au sévoflurane réduit le temps jusqu'à la PRC et permet une insertion du PLMA à la fois plus rapide et moins susceptible de provoquer des effets secondaires. La TS et la FC étaient toutes deux plus basses lors de l'administration de prémédication. Les patients recevant une prémédication étaient moins anxieux et moins susceptibles de se souvenir de l'application du masque facial. La prémédication a toutefois été associée à une FR plus basse et à des valeurs d'EtCO $\mathrm{O}_{2}$ plus élevées à la suite de l'insertion du PLMA, en dépit de concentrations plus faibles d'EtSevo. (ClinicalTrials.gov ID NCT00723164).

Owing to its unique non-pungency and low blood-gas partition coefficient, inhalation induction of anesthesia with sevoflurane (IIAS) in adults is an alternative to traditional intravenous induction. Inhaled induction allows for maintenance of spontaneous ventilation, ${ }^{1,2}$ which, in some patients, can facilitate airway management and help to preserve hemodynamic stability. ${ }^{3}$ Despite such advantages, IIAS is generally lengthier than intravenous induction and can be less satisfactory for patients. ${ }^{1-4}$ Several authors have studied the effect of adding a small dose of either a benzodiazepine or an opioid during IIAS and found that the pre-induction administration of sedative-hypnotics can accelerate induction, facilitate airway management, and increase patient satisfaction. ${ }^{5-7}$ The possible drawbacks of intravenous premedication include respiratory depression and episodes of apnea, thus decreasing speed of induction. ${ }^{8,9}$ Muzi et al. $^{10}$ demonstrated that combining fentanyl $0.6 \mu \mathrm{g} \cdot \mathrm{kg}^{-1}$ and midazolam $9 \mu \mathrm{g} \cdot \mathrm{kg}^{-1}$ was more advantageous to accelerate and improve tracheal intubation conditions during IIAS than administering a higher dose of either medication alone.

In this randomized controlled trial, our primary hypothesis was that a combination of low doses of intravenous fentanyl and midazolam would shorten time to loss of consciousness and laryngeal mask airway insertion time. Secondarily, each participant's cardiorespiratory status and anxiety and satisfaction levels were also evaluated.

\section{Methods}

This trial has been registered at the ClinicalTrials.gov website (ID: NCT00723164). The study protocol was approved by the Research and Ethics Review Board of MaisonneuveRosemont Hospital, and written informed consent was obtained from each participant. We recruited adults of both sexes aged 18-75 yr with ASA physical status I-II who were scheduled to undergo minor elective surgery under general anesthesia. Patients were excluded if they had a history of gastroesophageal reflux, if they exhibited a body mass index $>32 \mathrm{~kg} \cdot \mathrm{m}^{-2}$, or if they took sedative or opioid drugs. Although no toxicology screen was conducted, patients with a history of alcohol or drug abuse were also excluded. Prior to IIAS, a computer-generated table was used to randomly divide the subjects into two groups to receive either normal saline $2.5 \mathrm{~mL} i v$ (Group PLAC) or a combination of fentanyl $0.6 \mu \mathrm{g} \cdot \mathrm{kg}^{-1}$ and midazolam $9 \mu \mathrm{g} \cdot \mathrm{kg}^{-1}$ to which normal saline was added to obtain a volume of $2.5 \mathrm{~mL}$ (Group FM). The information regarding each participant's allocation was placed in a sealed envelope, and an independent anesthesiologist not involved with the patient's anesthesia care prepared the medication in a different room. A single investigator (S.L.) blinded to patients' allocation performed all of the IIAS. Prior to entering the operating room, all subjects, none of whom had received any premedication, were asked by the same investigator performing the IIAS to rate their anxiety level on a verbal numerical scale (VNS) from 0 to 10 ( 0 being the lowest and 10 being the highest anxiety level). Patients were then transferred into the operating room where standard monitors (non-invasive blood pressure, pulse oximetry, and five-lead EKG) were applied. A lactated Ringer's solution was started through a $20 \mathrm{G}$ intravenous catheter. At this stage, the VNS anxiety level was reassessed. At this point, all participants received $\mathrm{O}_{2}$ through a nasal cannula $\left(2 \mathrm{~L} \cdot \min ^{-1}\right)$, and the study medication was injected. Five minutes after injection, the VNS anxiety level was re-evaluated for a third time, just before beginning the IIAS. Subjects were asked to breathe normally through a face mask connected to a circle system prefilled with $8 \%$ sevoflurane in $100 \% \mathrm{O}_{2}$ at a flow rate of $6 \mathrm{~L} \cdot \mathrm{min}^{-1}$ (Dräger Fabius GS, Dräger Medical, Luebeck, Germany). The eyelash reflex was monitored every $15 \mathrm{sec}$ until it disappeared. Jaw relaxation was then assessed every $15 \mathrm{sec}$ until it was judged to be sufficient to allow for the insertion of a ProSeal $^{\mathrm{TM}}$ laryngeal mask airway (PLMA) (The Laryngeal 
Mask Company, Henley-on-Thames, UK), \#4 for women and \#5 for men, using the manufacturer's recommended technique. ${ }^{11}$ If PLMA insertion failed (inability to correctly position the PLMA for oxygenation and ventilation), the facemask was applied again and another attempt was made as soon as it was deemed possible. If participants exhibited upper airway obstruction during IIAS prior to PLMA insertion, a nasopharyngeal cannula could be inserted, but positive pressure ventilation was avoided.

Following PLMA insertion, the inspired sevoflurane concentration was decreased to $4 \%$ and the fresh gas flow rate was reduced to $3 \mathrm{~L} \cdot \mathrm{min}^{-1}$. For the first spontaneous three breaths following PLMA insertion, the end-tidal $\mathrm{CO}_{2}$ $\left(\mathrm{EtCO}_{2}\right)$ and sevoflurane (EtSevo) concentrations were recorded $\left(\mathrm{GE} \mathrm{Solar}{ }^{\circledR} 8000\right.$ \& 9500 monitoring system, GE Healthcare, Chalfont St. Giles, UK) and averaged. Adverse events (movements, cough, stridor, and episodes of apnea lasting longer than $15 \mathrm{sec}$ ) were recorded during IIAS and PLMA insertion. Spontaneous respiratory rate and tidal volume were then registered for the next $3 \mathrm{~min}$. Starting with the beginning of the IIAS, systolic blood pressure and heart rate were recorded every minute during a 10 -min period. Spontaneous breathing was maintained during the entire observation period. Surgical stimulation was not allowed before data collection was completed, and the remainder of the anesthetic management was at the discretion of the attending anesthesiologist.

All patients were contacted $24 \mathrm{hr}$ postoperatively by the principal investigator who had performed all IIAS, and they were asked the following questions: "Do you remember having a mask applied to your face before sleeping?" (Yes, no); "What is your appreciation level of the anesthesia induction technique?" (Very pleasant, pleasant, unpleasant, or very unpleasant); and "Would you choose the same technique for a future surgery?"

The primary outcome measurement was the time interval between the start of inhaled sevoflurane application until insertion of the laryngeal mask airway. Previous studies have shown that this time interval averaged around $135 \mathrm{sec}$ with a SD of $40 \mathrm{sec}^{3,4}$ We decided that a difference of $30 \mathrm{sec}$ in insertion time would be deemed clinically significant. Sample size calculation, accepting alpha and beta errors of 0.05 and 0.2 , respectively, suggested that 35 patients per group would be required. We enrolled 40 patients per group to account for potential dropouts. Statistical analyses were performed using Prism $^{\circledR} 3.0$ (GraphPad Software, La Jolla, CA, USA). Continuous data were analyzed using Student's $t$ test. Ordinal data and proportions were compared with Mann-Whitney $U$-test and Fisher's exact test, respectively. Two-way ANOVA was used to compare heart rate, systolic blood pressure, respiratory rate, and tidal volume between groups. If a significant difference was found, it was followed by Bonferroni's post hoc test. Unless stated otherwise, data are expressed as mean $\pm \mathrm{SD}$. A $P<0.05$ was considered to indicate statistically significant differences.

\section{Results}

This study took place at Hôpital Maisonneuve-Rosemont and patients were recruited during the period from October 11 to December 14, 2005. During this three-month period, 80 eligible patients accepted to enter the study, and they all completed the protocol without deviation, except for one patient belonging to Group FM who received $100 \mathrm{mg}$ of propofol because the attending anesthesiologist felt that her agitation and persistent cough prevented her from inhaling enough sevoflurane to deepen the anesthesia. She maintained spontaneous breathing and, except for postoperative measurements, her data were included in the statistical analysis. Demographic and surgical data of the participants are listed in Table 1. Mean times for loss of eyelash reflex (Group PLAC: $66 \pm 34 \mathrm{sec} v s$ Group FM: $47 \pm 18 \mathrm{sec}$, $P=0.0027$, difference $=19$ sec: $95 \%$ confidence interval (CI) 7-31 sec), and to PLMA insertion (Group PLAC:
Table 1 Demographic and surgical data

Data are presented as mean $\pm \mathrm{SD}$ (range) when applicable. PLAC placebo group; $F M$ fentanyl-midazolam group

\begin{tabular}{lll}
\hline & PLAC $(n=40)$ & FM $(n=40)$ \\
\hline Age $(\mathrm{yr})$ & $48.2 \pm 12.8(25-73)$ & $44.4 \pm 13.0(23-74)$ \\
Gender $(\mathrm{M} / \mathrm{F})$ & $11 / 29$ & $9 / 31$ \\
Height $(\mathrm{m})$ & $1.66 \pm 0.08(1.50-1.85)$ & $1.64 \pm 0.08(1.52-1.80)$ \\
Weight $(\mathrm{kg})$ & $67.9 \pm 12.3(47-95)$ & $67.9 \pm 11.0(45-90)$ \\
Smokers & 12 & 6 \\
Surgeries & & \\
$\quad$ Mastectomy & 13 & 11 \\
$\quad$ Gynecologic & 11 & 7 \\
$\quad$ Plastic & 5 & 4 \\
$\quad$ Ophthalmological & 3 & 7 \\
$\quad$ Others & 8 & 7 \\
\hline
\end{tabular}


Table 2 Induction time and PLMA insertion characteristics

\begin{tabular}{lllc}
\hline & $\begin{array}{l}\text { PLAC } \\
(n=40)\end{array}$ & $\begin{array}{l}\text { FM } \\
(n=40)\end{array}$ & $P$ \\
\hline $\begin{array}{l}\text { Time to loss of eyelash } \\
\text { reflex (sec) }\end{array}$ & $66 \pm 34$ & $47 \pm 18$ & $0.0027^{\mathrm{a}}$ \\
$\begin{array}{l}\text { Time to PLMA } \\
\quad \text { insertion (sec) }\end{array}$ & $186 \pm 80$ & $119 \pm 44$ & $<0.0001^{\mathrm{a}}$ \\
$\begin{array}{l}\text { Attempts (1/2) } \\
\text { EtCO }(\mathrm{mmHg})\end{array}$ & $33 / 7$ & $39 / 1$ & $0.057^{\mathrm{b}}$ \\
EtSevo $(\%)^{\mathrm{b}}$ & $37 \pm 6$ & $43 \pm 7$ & $<0.0001^{\mathrm{a}}$ \\
\hline
\end{tabular}

Data are presented as mean \pm SD when applicable

PLMA ProSeal ${ }^{\mathrm{TM}}$ laryngeal mask airway; PLAC normal saline group; $F M$ fentanyl-midazolam group; $E t C \mathrm{O}_{2}$ end-tidal $\mathrm{CO}_{2}$ partial pressure after PLMA insertion; EtSevo end-tidal sevoflurane concentration after PLMA insertion

a Unpaired Student's $t$ test

${ }^{\mathrm{b}}$ Fisher's exact test

Table 3 Adverse events during induction and PLMA insertion

\begin{tabular}{lccl}
\hline & PLAC $(n=40)$ & FM $(n=40)$ & $P$ \\
\hline At least one adverse event & 34 & 23 & 0.0126 \\
Movements & 28 & 18 & 0.04 \\
Cough & 9 & 3 & 0.11 \\
Apnea $(>15 \mathrm{sec})$ & 23 & 13 & 0.04 \\
Stridor & 13 & 6 & 0.11 \\
\hline
\end{tabular}

All data were analyzed with Fisher's exact test

PLAC normal saline group; $F M$ fentanyl-midazolam group

$186 \pm 80 \mathrm{sec} v s$ Group FM: $119 \pm 44 \mathrm{sec}, P<0.0001$, difference $=68 \mathrm{sec}: 95 \%$ CI $39-97 \mathrm{sec})$ were shorter in the premedicated FM group (Table 2). All PLMA insertions were achieved with either one or two attempts. In Group FM, 97.5\% of the PLMA were inserted on the first attempt compared with $82.5 \%$ in Group PLAC. End-tidal sevoflurane concentration values were lower and $\mathrm{EtCO}_{2}$ concentrations were higher in Group FM. Patients from Group PLAC experienced more adverse events (Table 3). More movements and apnea episodes were observed in Group PLAC, but no participant required positive pressure ventilation, and they all kept $\mathrm{O}_{2}$ saturation levels above $95 \%$. The incidence of cough and stridor was similar in the two groups. Two patients belonging to Group PLAC required insertion of a nasopharyngeal device to relieve airway obstruction during IIAS.

No differences were observed between groups regarding tidal volume during the first three minutes following PLMA insertion, although respiratory rates were lower in Group FM (Fig. 1). Following PLMA insertion, systolic blood pressure and heart rate values were significantly greater in Group PLAC compared with Group FM (Fig. 2).
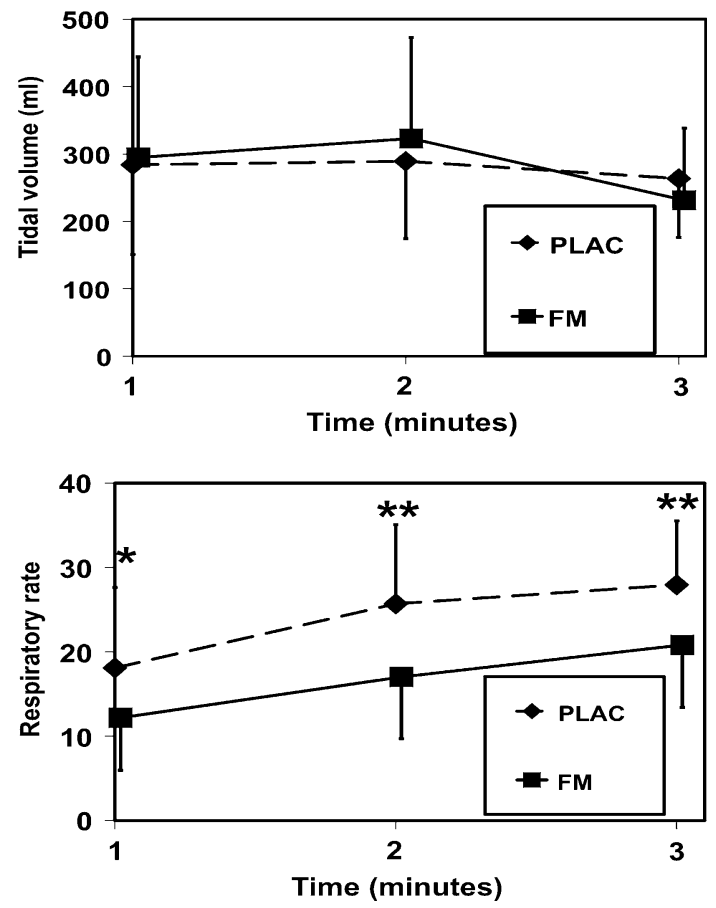

Fig. 1 Tidal volume (top) and respiratory rate (bottom) during the 3 min following PLMA insertion. PLAC placebo group; FM fentanylmidazolam group. Two-way analysis of variance (ANOVA): $P=0.8$ for tidal volume. Two-way ANOVA: $P<0.0001$ for respiratory rate followed by Bonferroni post-test: $* P<0.01$, ** $P<0.001$. Data are expressed as mean $\pm \mathrm{SD}$

Anxiety levels were similar between the two groups before and immediately after the subjects entered the operating room. Five minutes after the administration of the study medication and prior to IIAS, median anxiety levels were less in Group FM compared with Group PLAC (Fig. 3). Each participant of Group PLAC recalled the mask being applied to his/her face, compared with 27 of the 39 patients in Group FM $(P<0.0001)$. The satisfaction level was high in both groups. Ninety-five and $100 \%$ of participants in the PLAC and FM groups, respectively, stated that they would choose the same induction technique again. Only two patients in Group PLAC and one patient in Group FM rated the inhaled induction with sevoflurane as being either unpleasant or very unpleasant.

\section{Discussion}

The results of this study show that IIAS and PLMA insertion are facilitated by the administration of a combination of low doses of fentanyl $\left(0.6 \mu \mathrm{g} \cdot \mathrm{kg}^{-1}\right)$ and midazolam $\left(9 \mu \mathrm{g} \cdot \mathrm{kg}^{-1}\right)$. The mean time to loss of consciousness was reduced by nearly $20 \mathrm{sec}$ and the time required for PLMA insertion was reduced by $>60 \mathrm{sec}$. Fewer side effects, such as movement or apnea, were 

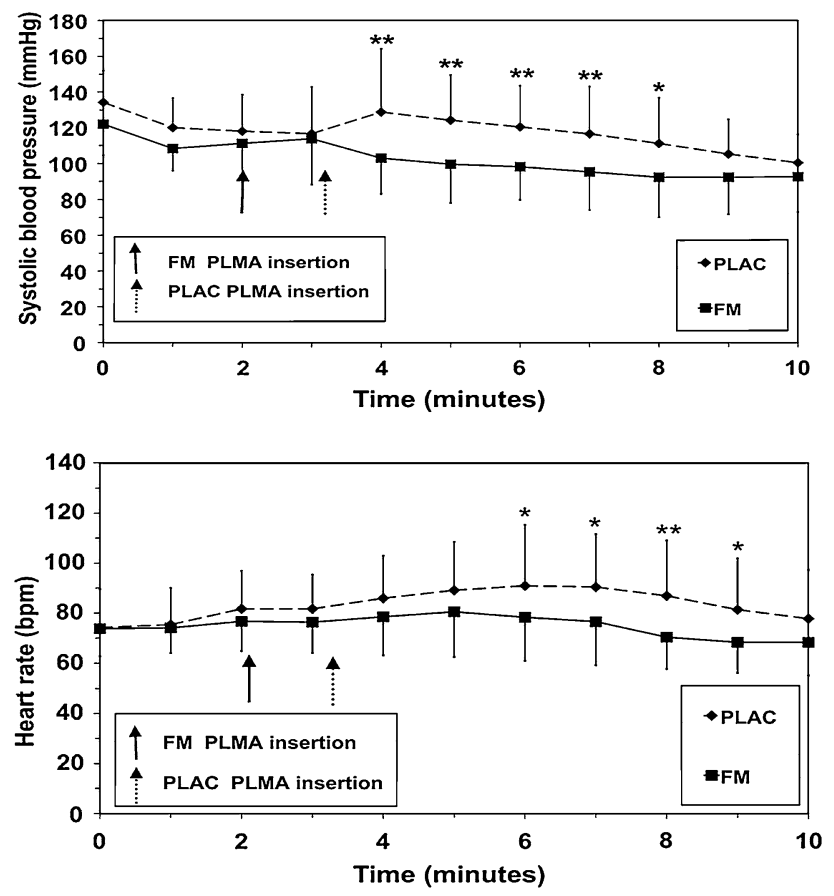

Fig. 2 Systolic blood pressure (top) and heart rate (bottom) during inhalation induction of anesthesia with sevoflurane (IIAS). Time zero is the beginning of the IIAS. PLAC placebo group; FM fentanylmidazolam group. Two-way analysis of variance: $P<0.0001$ for both systolic blood pressure and heart rate, followed by Bonferroni posttest: $* P<0.01,{ }^{* *} P<0.001$. Data are expressed as mean $\pm \mathrm{SD}$

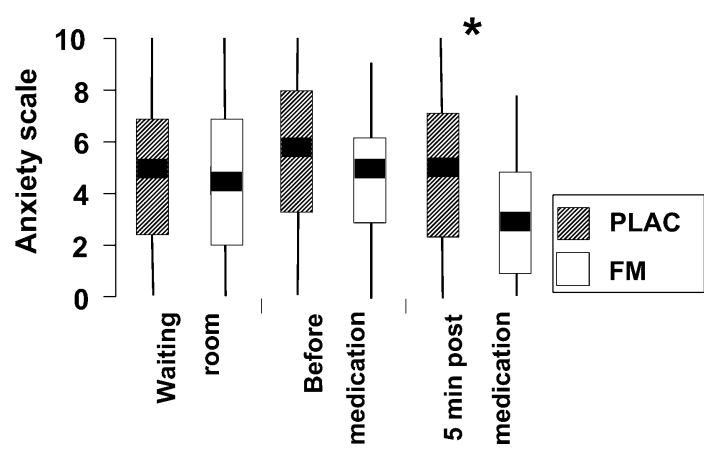

Fig. 3 Anxiety levels between groups before induction. PLAC placebo group; $F M$ fentanyl-midazolam group. Data were analyzed with the Mann-Whitney test. * A significant difference was observed 5 min post-medication: $P=0.0016$. The $P$ values in the waiting room and before the administration of the medication are 0.24 and 0.10 , respectively. Data are expressed as median, quartiles, and range

observed in the premedicated patients. Furthermore, fentanyl-midazolam was associated with decreased anxiety levels and absence of recall of the induction procedure in nearly one-third of patients.

Fentanyl-midazolam premedication also allowed PLMA insertion at lower EtSevo values. The MAC-sparing effect of both fentany $1^{12}$ and midazolam ${ }^{13,14}$ can probably explain these results. Still, authors who have studied the administration of opioids or midazolam alone prior to IIAS have found conflicting results. Some showed increased ${ }^{7-15}$ time to loss of consciousness or time needed before laryngeal mask insertion, while others showed a decrease..$^{5-10}$ The choice of drugs and doses in this study was influenced by Muzi et al. ${ }^{10}$ who showed that this particular combination accelerated and improved conditions for endotracheal intubation. Muzi's dosages were selected because of a previous study by Ben-Shlomo et al. ${ }^{14}$ showing that fentanyl and midazolam act synergistically and that $25 \%$ of the ED50 of fentanyl was required in combination with $23 \%$ of the ED50 for midazolam to achieve the ED50 of the combination. Still, contrary to Muzi et al., we opted for PLMA use instead of tracheal intubation. Therefore, maybe even lower dosages could have been appropriate, since PLMA insertion is far less stimulating than direct laryngoscopy and endotracheal intubation. We also examined patients' anxiety and satisfaction with the technique. Our study also included a placebo group, which Muzi et al. did not deem necessary, electing to refer to another study, also by his group, for comparison. ${ }^{16}$

In this study, the time to loss of eyelash reflex during IIAS without premedication, approximately $60 \mathrm{sec}$, is consistent with previous publications ${ }^{5,6,15-19}$ showing times ranging from 35 to $90 \mathrm{sec}^{2,4,7,20,21}$ These differences can be explained by the different ways IIAS can be performed. Basically, anesthesiologists may ask their patients to breathe normally or they may choose to rely on the singlebreath inhalation technique. ${ }^{4,6}$ Although the latter is praised by some,${ }^{22}$ its real efficacy is controversial ${ }^{20,21}$ and requires patient cooperation, which may be altered by premedication. For these reasons, we opted for the normal breathing approach. The use of $\mathrm{N}_{2} \mathrm{O}$ during IIAS has produced mixed results, most authors finding either little or no clinical benefit in adults. ${ }^{17,18}$ That, and the fact that it is customary in our institution to avoid $\mathrm{N}_{2} \mathrm{O}$ in most circumstances, prompted us to proceed without $\mathrm{N}_{2} \mathrm{O}$ in this study. The time needed before laryngeal mask insertion varies from 127 to $184 \mathrm{sec}$ amongst published works. ${ }^{4,77,18}$ The time observed in our study in unpremedicated subjects (186 sec) is somewhat longer than what has been reported. Again, these differences can be explained by the various manners in which IIAS is conducted and by the subjectivity of evaluating jaw relaxation.

In this study, there were fewer episodes of apnea in the fentanyl-midazolam group. Kelly et $a .^{23}$ reported similar results while studying desflurane inhalation induction with or without fentanyl-midazolam premedication. All the episodes of apnea they observed occurred in the placebo group. Aside from the pungency of desflurane that might have caused some of the participants in the Kelly et al. study to hold their breath, we can speculate that unpremedicated patients may have been hyperventilating when IIAS was started, thus lowering their arterial $\mathrm{pCO}_{2}$ below 
respiratory threshold. As a result, the combined effect of sevoflurane and hypocarbia could have provoked apnea when the patients lost consciousness. This hypothesis could explain why no patient in this study needed ventilatory assistance, their breathing resuming spontaneously when their arterial $\mathrm{pCO}_{2}$ increased sufficiently. It is also possible that the unpremedicated patients who exhibited increased minute ventilation were quicker to reach high EtSevo concentrations. The faster sevoflurane is administered the higher the chance the patient will become apneic. ${ }^{24}$ Respiratory irregularities can also contribute to the prolongation of IIAS. The deepening of inhalation anesthesia is obviously hampered by apnea, and this may have contributed to the longer intervals observed in our placebo group before loss of eyelash reflex and PLMA insertion. However, it is important to be careful before concluding that intravenous premedication during IIAS is always beneficial from a respiratory standpoint. It has been shown that administration of opioids alone, in doses higher than those used in this study, can provoke apnea during IIAS,, ,10 and even though we observed fewer episodes of apnea in the premedicated group, the administration of fentanylmidazolam was associated with lower respiratory rate and higher $\mathrm{EtCO}_{2}$ values following PLMA insertion. Both were likely caused by the premedication, since they occurred despite lower EtSevo concentrations in Group FM. Respiratory depression during IIAS may be a major concern, especially for patients with a difficult airway where it may be strongly advisable to maintain spontaneous breathing. Since none of the participants in this study had any obvious medical problem that could have exacerbated ventilatory depression, we suggest caution before concluding that premedication is safe in patients with respiratory compromise or in those exhibiting a potentially difficult airway.

The intravenous fentanyl-midazolam combination seems to have dampened the hemodynamic response to PLMA insertion. Other studies have shown that the use of a premedication during IIAS could lower systolic blood pressure and heart rate, but generally they remain within normal limits. ${ }^{7,8,15,25}$ The opioid part of the mixture is likely to be responsible for this effect. ${ }^{10}$ However, caution is warranted since adding opioids to IIAS, particularly sufentanil ${ }^{26}$ and remifentanil, ${ }^{27,28}$ has been linked to asystolic episodes.

This study suggests that premedication may be an attractive solution for reducing anxiety. A significant number of patients who received premedication did not remember breathing through a mask. The hypnotic proprieties of midazolam ${ }^{6}$ may well explain these findings. The high satisfaction level found in both groups is in line with those previously published. ${ }^{5,6}$ Still, data pertaining to satisfaction evaluation have to be considered with caution, since they can be easily influenced by factors such as the desirability bias. ${ }^{1,29}$
This study has several limitations. Amongst them, the fact that all inductions were performed by a single investigator may prompt some debate. Although a single operator facilitates standardization of the process, one cannot be certain that the results would have been reproducible with different anesthesiologists with different levels of experience with inhaled induction using sevoflurane. Furthermore, several endpoints, including the assessment of jaw relaxation and grading of PLMA insertion, are somewhat subjective. It is also possible that some of the effect of the premedication could have been detected by the investigator conducting the anxiety questionnaire, thus hinting at the group to which participants belonged. Finally, we chose to evaluate a fixed combination of drugs and doses that were recommended by Muzi et al. ${ }^{10}$ Dose-response data would be desirable, but the complexity of conducting dose response evaluations in the non-steady-state clinical setting of anesthetic induction makes such evaluations very difficult from a methodological perspective.

In conclusion, a low-dose combination of intravenous fentanyl-midazolam premedication administered $5 \mathrm{~min}$ before IIAS accelerates loss of consciousness and facilitates PLMA insertion. This drug combination is associated with fewer hemodynamic changes and helps to reduce patients' anxiety. This premedication combination is also associated with fewer episodes of apnea, although lower respiratory rates and higher $\mathrm{EtCO}_{2}$ values suggest that spontaneous ventilation is somewhat depressed.

Competing interests None declared.

\section{References}

1. Joo HS, Perks WJ. Sevoflurane versus propofol for anesthesic induction: a meta-analysis. Anesth Analg 2000; 91: 213-9.

2. Siddik-Sayyid SM, Aouad MT, Taha SK, et al. A comparison of sevoflurane-propofol versus sevoflurane or propofol for laryngeal mask airway insertion in adults. Anesth Analg 2005; 100: 1204-9.

3. Ganatra SB, D'Mello J, Butani M, Jhamnani P. Conditions for insertion of the laryngeal mask airway: comparisons between sevoflurane and propofol using fentanyl as a co-induction agent. A pilot study. Eur J Anaesthesiol 2002; 19: 371-5.

4. Ti LK, Chow MY, Lee TL. Comparison of sevoflurane with propofol for laryngeal mask airway insertion in adults. Anesth Analg 1999; 88: 908-12.

5. Hattori J, Yamakage M, Iwasaki S, Chen X, Tsujiguchi N, Namiki $A$. Usefulness of midazolam premedication for volatile induction of anesthesia in adults. J Anesth 2001; 15: 117-9.

6. Nishiyama T, Matsukawa T, Yokoyama T, Hanaoka K. Rapid inhalation induction with $7 \%$ sevoflurane combined with intravenous midazolam. J Clin Anesth 2002; 14: 290-5.

7. Sivalingam $P$, Kandasamy R, Madhavan G, Dhakshinamoorthi $P$. Conditions for laryngeal mask insertion. A comparaison of propofol versus sevoflurane with or without alfentanil. Anaesthesia 1999; 54: 271-6. 
8. Nathan N, Vaudroux D, Benrhaiem M, Marquet P, Preux PM, Feiss $P$. Low alfentanil target-concentrations improve hemodynamic and intubating conditions during induction with sevoflurane. Can J Anesth 2004; 51: 382-7.

9. Meaudre E, Boret H, Suppini A, Sallaberry M, Benefice S, Palmier B. Sufentanil supplementation of sevoflurane during induction of anesthesia: a randomized study. Eur J Anaesthesiol 2004; 21: 793-6.

10. Muzi M, Colinco MD, Robinson BJ, Ebert TJ. The effects of premedication on inhaled induction of anesthesia with sevoflurane. Anesth Analg 1997; 85:1143-8.

11. Brain AI. The Intravent Laryngeal Mask Instruction Manual. 2nd ed. Henley on Thames, England: Intravent International; 1993: p. 7.

12. Katoh T, Nakajima G, Moriwaki $G$, et al. Sevoflurane requirements for tracheal intubation with and without fentanyl. Br J Anaesth 1999; 82: 561-5.

13. Inagaki $Y$, Sumikawa $K$, Yoshiya I. Anesthetic interaction between midazolam and halothane in humans. Anesth Analg 1993; 76: 613-7.

14. Ben-Shlomo I, abd-el-Khalim H, Ezry J, Zohar S, Tverskoy M. Midazolam acts synergistically with fentanyl for induction of anaesthesia. Br J Anaesth 1990; 64: 45-7.

15. Plastow SE, Hall JE, Pugh SC. Fentanyl supplementation of sevoflurane induction of anaesthesia. Anaesthesia 2000; 55: 475-88.

16. Muzi M, Robinson BJ, Ebert TJ, O'Brien TJ. Induction of anesthesia and tracheal intubation with sevoflurane in adults. Anesthesiology 1996; 85: 536-43.

17. Hall JE, Stewart JI, Harmer M. Single-breath inhalation induction of sevoflurane anaesthesia with and without nitrous oxide: a feasibility study in adults and comparaison with an intravenous bolus of propofol. Anaesthesia 1997; 52: 410-5.

18. Siau $C$, Liu EH. Nitrous oxide does not improve sevoflurane induction of anaesthesia in adults. J Clin Anesth 2002; 14: 218-22.
19. Philip BK, Lombard LL, Roaf ER, Drager LR, Calalang I, Philip $J H$. Comparaison of vital capacity induction with sevoflurane to intravenous induction with propofol for adult ambulatory anesthesia. Anesth Analg 1999; 89: 623-7.

20. Yogendran S, Prabhu A, Hendy A, et al. Vital capacity and patient controlled sevoflurane inhalation result in similar induction characteristics. Can J Anesth 2005; 52: 45-9.

21. Baker CE, Smith I. Sevoflurane: a comparaison between vital capacity and tidal breathing techniques for the induction of anaesthesia and laryngeal mask airway placement. Anaesthesia 1999; 54: 841-4.

22. Nathan N, Bazin JE, Cros AM. Induction par inhalation. Ann Fr Anesth Réanim 2004; 23: 884-99.

23. Kelly RE, Hartman GS, Embree PB, Sharp G, Artusio JF Jr. Inhaled induction and emergence from desflurane anesthesia in the ambulatory surgical patient: the effect of premedication. Anesth Analg 1993; 77: 540-3.

24. Pancaro C, Giovannoni S, Toscano A, Peduto VA. Apnea during induction of anesthesia with sevoflurane is related to its mode of administration. Can J Anesth 2005; 52: 591-4.

25. Joo HS, Perk WJ, Belo SE. Sevoflurane with remifentanil allows rapid tracheal intubation without neuromuscular blocking agents. Can J Anesth 2001; 48: 646-50.

26. Cardinal V, Martin R, Tetrault JP, Colas MJ, Gagnon L, Claprood $Y$. Bradycardie sévère et asystolie lors d'induction au sévoflurane et sufentanil à faible dose: à propos de trois cas. Can J Anesth 2004; 51: 806-9.

27. Wang J, Winship S, Russell G. Induction of anaesthesia with sevoflurane and low-dose remifentanil: asystole following laryngoscopy. Br J Anaesth 1998; 81: 994-5.

28. Kurdi O, Deleuze A, Marret E, Bonnet F. Asystole during anaesthetic induction with remifentanil and sevoflurane. $\mathrm{Br} \mathrm{J}$ Anaesth 2001; 87: 943.

29. Le May S, Hardy JF, Taillefer MC, Dupuis G. Measurement of patient satisfaction. Anesth Analg 1999; 89: 255. 